\title{
DEVELOPMENT OF CERAMIC CUTTING TOOLS FOR FUTURE APPLICATION ON DRY MACHINING
}

\author{
O.M.M. Silva ${ }^{1}$, J.V.C. Souza, ${ }^{2,3}$, M. C. A. Nono ${ }^{2}$, G. V. Martins ${ }^{2}$, \\ M.V. Ribeiro ${ }^{4}$, J. P. B. Machado ${ }^{2}$ \\ ${ }^{1}$ CTA-IAE/AMR - Pça. Marechal do Ar E. Gomes, 50, S. J. C. - SP, CEP. 12228-904, Brazil \\ ${ }^{2}$ INPE - Av. dos Astronautas, 1.758, S. J. Campo s - SP, CEP. 12245-970, Brazil \\ ${ }^{3}$ UNIFOA, Av. Paulo E. A. Abrantes, 1.325, Volta Redonda - RJ, CEP. 27240-560,Brazil \\ ${ }^{4}$ FEG-UNESP - Av. Dr Ariberto P. da Cunha, 333, Guaratinguetá - SP, CEP 12516-410, \\ Brazil \\ vitor@las.inpe.br
}

\section{Keywords: $\mathrm{Si}_{3} \mathrm{~N}_{4}$; Dry machining; Ceramics; New cutting tool.}

\begin{abstract}
Advanced ceramic materials constitute a mature technology with a very broad base of current and potential applications and a growing list of material compositions. Within the advanced ceramics category, silicon nitride based ceramics are wear-resistant, corrosionresistant and lightweight materials, and are superior to many materials with regard to stability in high-temperature environments. Because of this combination the silicon nitride ceramics have an especially high potential to resolve a wide number of machining problems in the industries. Presently the $\mathrm{Si}_{3} \mathrm{~N}_{4}$ ceramic cutting tool inserts are developed using additives powders that are pressed and sintered in the form of a cutting tool insert at a temperature of $1850{ }^{\circ} \mathrm{C}$ using pressureless sintering. The microstructure of the material was observed and analyzed using XRD, SEM, and the mechanical response of this array microstructure was characterized for hardness Vickers and fracture toughness. The results show that $\mathrm{Si}_{3} \mathrm{~N}_{4} / 20$ wt.\% (AlN and $\mathrm{Y}_{2} \mathrm{O}_{3}$ ) gives the best balance between hardness Vickers and fracture toughness. The $\mathrm{Si}_{3} \mathrm{~N}_{4} / 15 \mathrm{wt} . \%\left(\mathrm{AlN}\right.$ and $\mathrm{Y}_{2} \mathrm{O}_{3}$ ) composition allows the production of a very fine-grained microstructure with low decreasing of the fracture toughness and increased hardness Vickers. These ceramic cutting tools present adequate characteristics for future application on dry machining.
\end{abstract}

\section{Introdution}

Advances in ceramic composites have resulted in the emergence of newer materials [1]. Control of microstructures has led to the development of new ceramic composite materials which are successfully used for cutting tool applications [2 and 3].There is a continuous need for improving the existing cutting tool materials, which is driven by a strong competition on the market and also by more difficult to machine materials like, e.g. high alloyed grey cast iron, compacted graphite iron, nickel alloys [4]. $\mathrm{Si}_{3} \mathrm{~N}_{4}$ ceramic cutting tools offer a high productivity due to their excellent hot hardness, which allows high cutting speeds. Under such conditions the cutting tool must be resistant to a combination of mechanical, thermal and chemical attacks [5]. Machining, a major manufacturing process, plays a key role in overall manufacturing costs. The development of new ceramic cutting tools that have unique chemical and mechanical properties is important as these tools can offer an increase in metal removal rates, extending tool life and having the ability to machine harder materials too. When properly applied these tools can provide the manufacturing engineer with a means of reducing machining costs and increasing productivity [4]. Machining with silicon nitride ceramic tools is usually carried out in dry condition. In general, environmental concerns call for the reduction of cutting fluids in industry [6]. The concept of dry machining has many advantages, such as non-pollution of the atmosphere or water, no residue or the swarf resulting in the reduction of disposal and cleaning cost, no danger to health, such as skin 
rupture and allergy [7]. This prompts researchers to develop ceramic cutting tool materials with high dry machining performance. In recent work the authors has been proved the great potential of silicon nitride on dry machining [8]. Some researchers have adopted a method of mist lubrication [9]. Depending on the machined workpiece, cost savings up to $17 \%$ of the total work piece cost can be made by introducing dry machining. This is mainly due to the elimination of coolant supply, cleaning, maintenance and disposal costs [10]. Reducing costs in the cutting process together with reduced environmental pollution by the use of dry machining is the main key for the industry to remain competitive and profitable in the future $[11,12]$. In this way, the present work investigates the possibility of increasing silicon nitride cutting tools properties so that it can be used, with higher efficiency compared to the cutting tools available in the market, on dry machining.

\section{Wear mechanism of ceramic cutting tools}

In general, ceramic cutting tools undergo wear due to abrasion, adhesion or diffusion. The total tool wear observed in the ceramic tool can be divided into two main broad categories [13]:

- Mechanically activated wear which includes abrasion, adhesion (attrition) and fracture;

- Chemically activated wear which includes diffusion or dissolution wear.

Usually the wear in a cutting tool is a complex phenomenon and can be attributed to several of the above wear modes/mechanisms. The combined effect of the wear mechanisms or the predominance of any of them depends upon the following factors:

- type of cutting tool material such as single phase ceramic or composite ceramic, type of reinforcements like particles, whiskers, chemical affinity towards work piece material, mechanical properties such as hardness, toughness etc.;

- type of work piece material such as ferrous or non-ferrous material, composite material, its hardness and machinability;

- cutting conditions such as speed, feed rate, depth of cut, and tool geometry such as rake angle, clearance angle, approach angle, cutting edge angle, nose radius etc.

In general ceramic cutting tool materials are more wear resistant than cemented carbide tools. Abrasive wear is predominantly controlled by the mechanical properties of tool material such as hardness and toughness. Diffusion wear is predominantly controlled by chemical stability and the solubility of the tool material in the work material at high temperature.

\section{Cutting tools for machining super-alloys.}

The requirements for any cutting tool material used for machining super-alloys are [14]: good wear resistance, high hot hardness, high strength and toughness, good thermal shock properties and adequate chemical stability at elevated temperature.

\section{Experimental procedure}

Two different $\mathrm{Si}_{3} \mathrm{~N}_{4}$-based compositions were prepared using the following high purity starting powders: SNYA1, $85.0 \alpha-\mathrm{Si}_{3} \mathrm{~N}_{4}-5.0 \mathrm{Y}_{2} \mathrm{O}_{3}-10.0 \mathrm{AlN}$ (H. C. Starck) and SNYA2, $80.0 \alpha-\mathrm{Si}_{3} \mathrm{~N}_{4}-8.0 \mathrm{Y}_{2} \mathrm{O}_{3}-12.0 \mathrm{AlN}$ (H. C. Starck) in wt. \% to obtain different ceramics cutting tools. The starting powders were weighed and milled in water-free isopropyl for $8 \mathrm{hrs}$. in an agate jar using agate milling media. The mixed powders were dried and subsequently sieved. The green bodies were fabricated by uniaxial pressing under a $50 \mathrm{MPa}$ pressure and subsequent isostatic pressing under a $300 \mathrm{MPa}$ pressure. After compaction, samples showed dimensions of $15.86 \times 15.86 \times 6.5 \mathrm{~mm}$ and green density of $60 \%$ by geometric methods. Before sintering, the samples were involved in $70 \% \mathrm{Si}_{3} \mathrm{~N}_{4}+30 \% \mathrm{BN}$ as powder bed, and 
then introduced in a furnace with a graphite heating element (Thermal Technology Inc. type $1000-4560-F P 20)$ in a nitrogen atmosphere. The heating rate employed was $25^{\circ} \mathrm{C} / \mathrm{min}$. up to a maximum sintering temperature of $1850{ }^{\circ} \mathrm{C}$, with a holding time of 2 hours. The cooling rate was the same as the heating rate. The density of the samples was measured by the Archimedes method and the weight loss was determined before and after sintering measurements. The surfaces of the sintered samples were removed (at least $2 \mathrm{~mm}$ ) and then the phase composition was analyzed by the X-ray diffraction technique. Microstructural characterization was performed with a scanning electron microscope (SEM). The samples for SEM examination were polished and submitted to chemical etching, in a $\mathrm{NaOH}: \mathrm{KOH}$ mixture $(1: 1$ at 500 ${ }^{\circ} \mathrm{C} / 10$ minutes), to reveal microstructure.

The hardness was determined by Vicker's indentations under an applied load of $20 \mathrm{~N}$ for 30 s. For statistical reasons, 20 indentations were made to each sample. The fracture toughness was determined by the measurement of crack length created by indentations. The calculation of the fracture's toughness values was done through a relation proposed by Evans et al., valid for Palmqvist-type cracks, conform to equation (1) $[15,16]$.

$$
\mathrm{K}_{\mathrm{IC}}=0.16(\mathrm{E} / \mathrm{HV})^{1 / 2} \cdot \mathrm{F} \cdot \mathrm{b}^{-3 / 2}
$$

Where: $\mathrm{K}_{\mathrm{IC}}=$ fracture toughness $\left[\mathrm{MPa}^{1 / 2} \mathrm{~m}^{1 / 2} \mathrm{E}=\right.$ Young modulus of material [GPa]; HV $=$ Vickers hardness $[\mathrm{GPa}] ; \mathrm{b}=\operatorname{crack}$ size $[\mu \mathrm{m}]$ and $\mathrm{F}=$ applied load $[\mathrm{N}]$.

\section{Results and discussion Sintering}

The particle size distributions of both powder batches, SNYA1 and SNYA2, showed that the average particle size found was approximately $0.48-0.62 \mu \mathrm{m}$, resulting in very similar green densities of both green samples. The SNYA2 sample had $98.75 \pm 0.16 \%$ relative density slightly higher than SNYA1 sample which had $97.92 \pm 0.22 \%$ relative density. The mass losses during the sintering were about $2 \%$ in both samples. This behavior demonstrates the viability of using $\mathrm{Y}_{2} \mathrm{O}_{3} / \mathrm{AlN}$ as sintering additives, promoting similar sintering activity for both samples compositions, as expected because of the same additives with only slightly different amounts. Thus the sintering parameters applied are adequate to produce high density cutting tools.

\section{X-ray difractometry (XRD)}

The sintered SNYA1 sample showed $\beta-\mathrm{Si}_{3} \mathrm{~N}_{4}$ present as the main matrix phase Fig.1. The randomly distributed grains of $\mathrm{Si}_{3} \mathrm{~N}_{4}$ ceramic fabricated through $\mathrm{N}_{2}$-pressure sintering lead to isotropic mechanical and physical properties [17]. The phase of $\mathrm{Y}_{2} \mathrm{Si}_{3} \mathrm{O}_{3} \mathrm{~N}_{4}$ was identified from the XRD spectra and the formation of this phase can be explained by the following reaction equation.

$$
\mathrm{Y}_{2} \mathrm{O}_{3}+\mathrm{Si}_{3} \mathrm{~N}_{4} \rightarrow \mathrm{Y}_{2} \mathrm{Si}_{3} \mathrm{O}_{3} \mathrm{~N}_{4}
$$

The X-ray diffraction pattern of a sample designated as SNYA2 $\left(\mathrm{N}_{2}\right.$-pressure sintering at $1850{ }^{\circ} \mathrm{C}$ ) is shown in Fig. 2. As seen in Fig. 2, a majoritary $\alpha$-SiAlON phase was identified suggesting the existence of a sintering-complete system. Fig. 2 shows the relationship between the phase formation and the amount of additive which will reflect in an increase of mechanical properties while the $\mathrm{Y}_{2} \mathrm{Si}_{3} \mathrm{O}_{3} \mathrm{~N}_{4}$ phase disappears. A higher sintering temperature of $1850{ }^{\circ} \mathrm{C}$ and a $20 \%$ amount of additive was effective to improve the mechanical properties and reduce the intergranular phase. Therefore, in this work, samples with 15 and $20 \%$ $\mathrm{Y}_{2} \mathrm{O}_{3} / \mathrm{AlN}$, as sintering additives, were completely densified with similar results presented by Santos et al.[18]. 


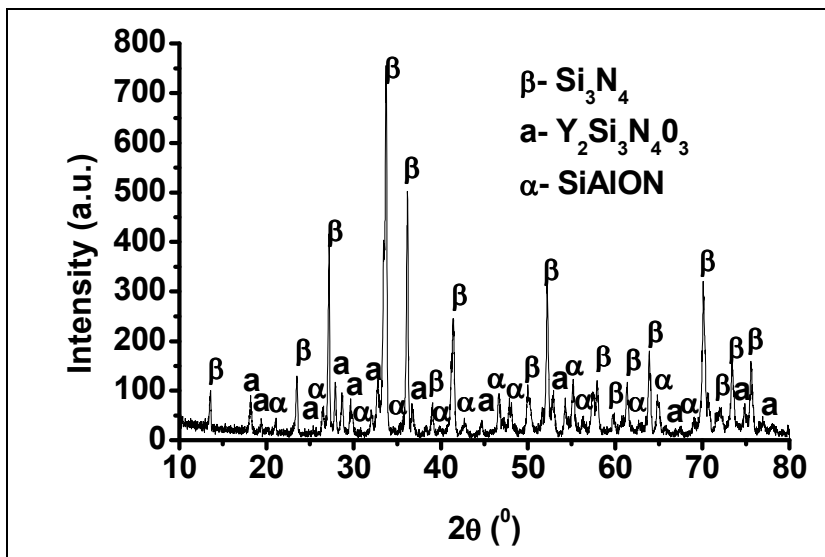

Fig. 1. X-ray diffraction patterns of SNYA1.

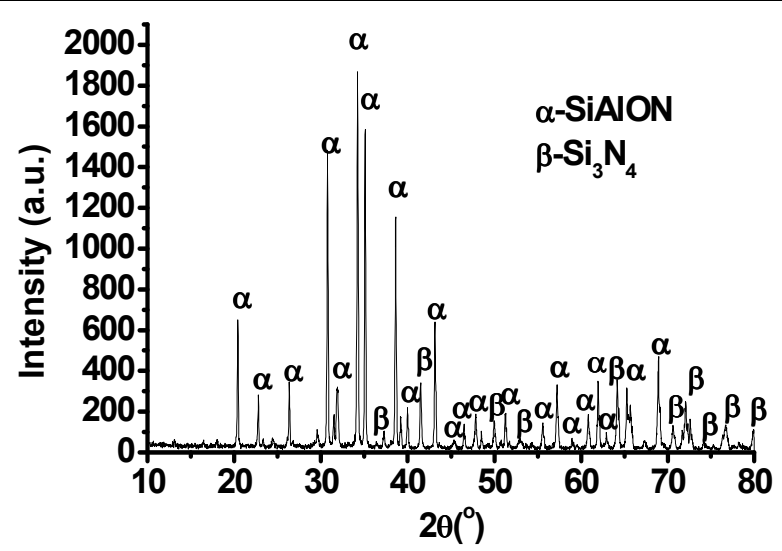

\section{Microstructure and mechanical properties}

As shown in Fig. 3, the microstructure of SNYA1 consists of elongated $\beta-\mathrm{Si}_{3} \mathrm{~N}_{4}$ grains randomly distributed in a matrix. The elongated $\beta-\mathrm{Si}_{3} \mathrm{~N}_{4}$ grains are well developed and have an irregular cross-section perpendicular to the growth direction. The $\beta-\mathrm{Si}_{3} \mathrm{~N}_{4}$ grains have an average grain size of about $4.5 \mu \mathrm{m}$ and aspects ratios higher than $5.1 \mu \mathrm{m}$. This demonstrates the efficiency of the gas-pressure sintering process $[19,20]$. The intergranular phase located between the grains was revealed and created during the etching-off of the grain-boundary phase.

In order to examine the effect of the amount of additives on the microstructure and morphology of $\mathrm{Si}_{3} \mathrm{~N}_{4}$ ceramic cutting tool, the micrograph of a sample of (SNYA2) sintered at temperatures of $1850^{\circ} \mathrm{C}$ is illustrated in Fig 4. At lower amount of additive, most of the $\alpha$ SiAlON grains are equiaxed and small. As the amount of additive increases, the volume fraction and the average quantity of $\alpha$-SiAlON grains also increases. In a previous report, the formation of the elongated $\alpha$-SiAlON grains was explained by means of the reduction of the driving force for the nucleation [9]. These studies show that the formation of elongated grains is directly related to the sintering parameters, time, temperature and isothermal holding time, as well as to the characteristics of the starting powders [21].

In Fig.4, one can appreciate the change in the average grain size of about $3.8 \mu \mathrm{m}$ and aspect ratios higher than $4.2 \mu \mathrm{m}$, thus confirming the formation of $\alpha$-SiAlON with an elongated microstructure.

In this paper, it was also possible to evaluate the effect of material density on hardness. The SNYA1 and SNYA2 compositions showed variations of hardness with density. As expected, the hardness of SNYA2 increases with increasing relative density and the highest value for hardness $(21.52 \mathrm{GPa})$ is achieved in the sample with the highest relative density, i.e., $98.75 \%$. Similar results for the variation of hardness with density were observed in the SNYA1 sample, which presented a decrease of hardness $(18.90 \mathrm{GPa})$ when decreasing relative density value.

It is interesting to note that the growth of elongated $\beta-\mathrm{Si}_{3} \mathrm{~N}_{4}$ grains occurred in the SNYA1 composition investigated, suggesting that the self-reinforcement for this composition is operational and may lead to an enhancement in toughness. In addition to composition, it was found that the amount of additive has an equally important role in promoting the growth of the elongated grains and volume fraction. The SNYA2 composition showed the change of the average grain aspect ratio and grain volume fraction of $15 \%$ additive, sintered at temperatures of $1850{ }^{\circ} \mathrm{C}$, the same as for the amount of additive of $20 \%$ : for both the grain aspect ratio decreased and the volume fraction of the grains increased. 
The effect of grain aspect ratio and elongated grain volume fraction is observed on fracture toughness for samples sintered with different amounts of additive. The results showed clearly that there is a relationship between fracture toughness and both the grain aspect ratio and volume fraction of the elongated grains. Unlike for the aspect ratio and volume fraction of the elongated grains, no definite relationship exists between fracture toughness and grain diameter (grain width). However the SNYA1 sample has shown a fracture toughness of $5.92 \mathrm{MPa} \mathrm{m}^{1 / 2}$ and the SNYA2 sample a fracture toughness of $5.45 \mathrm{MPa} \mathrm{m}^{1 / 2}$.

Despite the clear difference in grain morphology and toughness values, the SNYA2 sample has a high hardness of over $21 \mathrm{GPa}$. This is because the high hardness of $\alpha$-SiAlON ceramics, that is an intrinsic property, and is derived from the crystal structure. The longer atomic stacking sequence $(\mathrm{ABCD})$ in $\alpha$-SiAlON increases the slip resistance of the dislocations, offering a higher hardness compared to $\beta-\mathrm{Si}_{3} \mathrm{~N}_{4}$ or $\beta-\mathrm{SiAlON}$, which have a relatively lower hardness $(15-16 \mathrm{GPa})$ due to the shorter atomic stacking sequence $(\mathrm{AB})$.

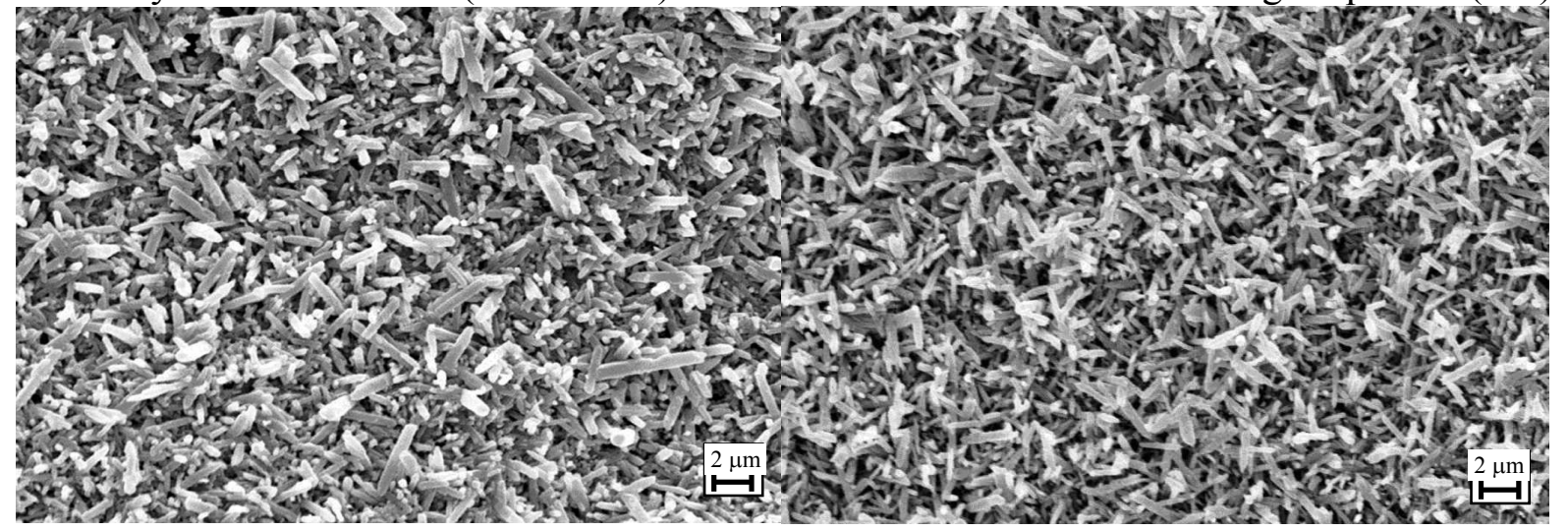

Fig. 3. SEM micrograph of sintered SNYA1.

Fig. 4. SEM micrograph of sintered

SNYA2.

\section{Conclusion}

It can be concluded that the experimental methodology applied here was effective in the development of new ceramic cutting tool inserts $\left(\beta-\mathrm{Si}_{3} \mathrm{~N}_{4}\right.$ and $\left.\alpha-\mathrm{SiAlON}\right)$, with high relative density, high hardness, fracture toughness and promising application on dry machining. It can be considered as an enabling technology which has potential to deliver high-value contributions for solving the challenges of the future machining industries. Optimized combination of properties governed by crystal chemistry and microstructure realized a new cutting tool material. The significance of these results will be further supported and explained in a more detailed manner by dry machining tests. To remain competitive in the future, and to ensure long-term success, machining policy makers, must focus on future markets of ceramic cutting tools and apply a well-founded strategy for technology development.

\section{Acknowledgement}

The authors would like to thank CAPES and FAPESP for their financial support.

\section{References}

[1] M. Mitomo and G. Petzow: MRS Bull. Vol. 2 (1995), p. 19.

[2] T. Sornakumar, M.V. Gopalakrishnan, R. Krishnamurthy and C.V. Gokularathnam: Int J Refract Metals Hard Mater Vol. 13(6) (1995), p. 375. 
[3] I.-W. Chen and A. Rosenflanz: Nature Vol. 389 (16) (1997), p. 701.

[4] J.V.C. Souza, M.C.A. Nono, M.V. Ribeiro, J.P.B. Machado and O.M.M. Silva: Materials \& Design, doi:10.1016/j.matdes.2008.09.041.

[5] Bernd Bitterlich, Sebastian Bitsch and Kilian Friederich, Journal of the European Ceramic Society v. 28, (2008), p. 989-994.

[6] P.S. Sreejith and B.K.A. Ngoi: J. Mater. Process. Technol. Vol.101 (2000), p. 287.

[7] D. Jianxin, C. Tongkun and L. Lili: J. Eur. Ceram. Soc. Vol. 25 (2005), p. 1073.

[8] J.V.C. Souza, M.C.A. Nono, M.V. Ribeiro and O.M.M. Silva: Materials Science Forum Vol. $591 / 593$ (2008), p. 565.

[9] A.S. Varadarajan, P.K. Philip and B. Ramamoorthy: Int. J. Mach. Tools Manuf. Vol. 42 (2002), p. 193.

[10] M. Lahres, O. Doerfel and R. Neumüller: Surface and Coatings Technology Vols. 120121 (1999), p. 687.

[11] E. Brinksmeier, A. Walter, R. Janssen and P. Diersen: Proceedings of the Institution of Mechanical Engineers 213 Part B (1999), p. 769.

[12] H. Popke, Th. Emmer and J. Steffenhagen: Proceedings of the Institution of Mechanical Engineers Vol. 213 Part B (1999), p. 329.

[13] G.W. Stachowiak and G.B. Stachowiak: Key Eng. Mater. 96 (1994), p. 137.

[14] J.V.C.Souza, et al.: 7 th International Conference on Advanced Manufacturing Systems and Technology, Udine June, 2005. Proceeding...2005 Udine (Italy).

[15] S.Y. Luo, Y.S. Liao and Y.Y. Tsai: J Mater Process Technol Vol. 88 (1999), p. 114.

[16] Sunil Dutta: Century: Bull Mater Sci Vol. 24 (2001) (2), p. 117.

[17] Y.K. Jeong and K. Niihara: Nano-struct Mater Vol. 9 (1-8) (1997), p. 193.

[18] C. Santos, K. Strecker, S. Ribeiro, J.V.C. Souza, O.M.M. Silva and C.R.M. Silva: Mater. Lett. Vol. 58 (2004), p. 1794.

[19] H. Mandal: J. Eur. Ceram. Soc. Vol. 19 (1999), p. 2349.

[20] Z.J. Shen, L-O. Nordberg, M. Nygren and T. Ekström: $\alpha$-SiAlON grains with high aspect ratio - Utopia or Reality. In: G.N. Babini, M. Haviar and P. Sajgalik, Editors, Engineering Ceramics 96; Higher Reliability Trough Processing, Kluwer Academic, The Netherland (1997), pp. 169-177.

[21] G. Woetting, B. Kanka and G. Ziegler, Microstructural characterization, and relation to mechanical properties of dense silicon nitride. In: S. Hampshire, Editor, Non-Oxide Technical and Engineering Ceramics, (Elsevier, London 1986), p. 83-96. 
Advanced Powder Technology VII

doi:10.4028/www.scientific.net/MSF.660-661

Development of Ceramic Cutting Tools for Future Application on Dry Machining doi:10.4028/www.scientific.net/MSF.660-661.724 